\title{
Apoptotic Effects of Melandryum firmum Root Extracts in Human SH-SY5Y Neuroblastoma Cells
}

\author{
Md. Ataur Rahman ${ }^{1}$, Haijie Yang ${ }^{1}$, Soon-Sung Lim ${ }^{2}$ and Sung-Oh Huh ${ }^{1 *}$ \\ ${ }^{1}$ Department of Pharmacology, College of Medicine, Institute of Natural Medicine, Hallym University, \\ ${ }^{2}$ Department of Food Science and Nutrition, College of Natural Science, Hallym University, Chuncheon 200-702, Korea
}

\begin{abstract}
Melandrium firmum is a biennial plant that has been used in traditional medicine for treatment of bacterial and fungal infection. Here, we investigated molecular mechanisms underlying apoptotic effects of Melandrium firmum root extract (MFRE) in neuroblastoma cells, since the effect of this natural compound on cancer cells has not been fully clarified. The root extract of $M$. firmum reduced cell proliferation, as revealed by cell viability assay. However, MFRE-treated cells exhibited morphological changes including cell rounding, neurite retraction and membrane blebbing. These alterations of cellular shape suggest this morphological change might be due to the apoptosis which shows fragmented DNA. In addition, MFRE up-regulated the pro-apoptotic protein Bax and down-regulated the anti-apoptotic protein Bcl-2 and Mcl-1, which also finally activated cleaved caspase-3 in a dose-dependent manner, as determined by western blot analyses. Together, these findings demonstrate that apoptotic and cytotoxic effects of MFRE on SH-SY5Y cells are mediated by intrinsic mitochondria-mediated caspase pathway and that this natural extract might be effective as an anticancer agent for neuroblastoma malignancies.
\end{abstract}

Key words: Melandryum firmum, neuroblastoma, apoptosis, caspase, anticancer

\section{INTRODUCTION}

Melandrium firmum is a biennial herbaceous plant widely distributed in Korea that is used to treat anuria, breast cancer, gonorrhea, and diseases of lactation [1]. Several sapogenins [2], a saponin [3], flavonoids and triterpenoids [4] have been identified in Melandrium firmum and their pharmacological actions have been evaluated. However, the effects of MFRE on neuroblastoma cancer and its mechanisms of action have yet to be elucidated. In this investigation, we employ neuroblastoma cancer and normal

Received September 3, 2013, Revised September 11,2013,

Accepted September 11,2013

${ }^{*}$ To whom correspondence should be addressed. TEL: 82-33-248-2615, FAX: 82-33-248-3188 e-mail:s0huh@hallym.ac.kr fibroblast cells to examine the therapeutic effects.

Neuroblastoma, one of the few human malignancies known to demonstrate spontaneous regression from an undifferentiated state to a completely benign cellular appearance originating from the sympathetic nervous system, is the most frequently occurring extra-cranial malignancy in childhood $[5,6]$. However, despite many advances in diagnosis and standard interventions in the past three decades, neuroblastoma has remained a formidable challenge to clinical and basic scientists [7]. Despite multimodal therapeutic approaches including chemotherapy, radio therapy, and immunotherapy, the survival rate for patients with malignant neuroblastoma remains poor. Newer therapeutic strategies are urgently warranted for successful treatment of this devastating childhood malignancy. Therefore, the need exists to develop novel agents to improve treatment outcomes in this high-risk group. In particular, we would search for novel therapeutic strategies for 
neuroblastoma; natural products have attracted interest to achieve a new approach currect chemotherapy treatment. To address this new found of interest, we have here reassessed natural products which have been used to combat disease for thousands of years and have demonstrated potent antitumor properties [8].

However, apoptosis can be triggered by a death receptor-dependent extrinsic pathway and mitochondria-mediated intrinsic pathway [9]. Therefore, changes in expression of the Bcl-2 family members resulting in decreased anti-apoptotic (e.g., Bcl-2, Bcl$\mathrm{xL}$ ) and increased pro-apoptotic (e.g., Bax, Bak) proteins may cause mitochondrial release of several pro-apoptotic molecules [10]. Most types of apoptosis induced by cellular stress (notably anticancer treatment) involve caspase- 3 as a major executioner, which upon activation cleaves cytosolic inhibitor of caspaseactivated DNase (ICAD) to release and translocate caspaseactivated DNase (CAD) to the nucleus for nuclear DNA fragmentation, the final event of apoptosis [11]. It is noteworthy that in the present work, we have shown that the expression of caspases specifically cleaves various endogenous cellular substrates and induces morphological and biochemical features of apoptosis [10, 12] by MFRE-induced cytotoxicity in human SH-SY5Y cancer cells.

The precise molecular mechanism(s) of MFRE-induced apoptosis in human neuroblastoma cells and its anti-cancer effect has not yet been elucidated. A new dimension in the management of neoplasia was the increasing awareness that chemoprevention, which refers to the administration of chemical agents to prevent the events associated with carcinogenesis [13]. A large number of chemopreventive and chemotherapeutic agents have been discovered from natural products and these provide a promising strategy to fight against cancer by inducing apoptosis in malignant cells $[14,15]$. To further explore the mechanism for these properties of MFRE, in this study we examined the effects of MFRE on neuroblastoma cells which initially compared with normal fibroblast cells. We also investigated the apoptotic induction of MFRE on human SH-SY5Y neuroblastoma cells by detecting cell viability, morphological changes and the expressions of the apoptotic relative proteins like Bcl-2 family and caspases.

\section{MATERIALS AND METHODS}

\section{Materials}

Roots of Melandryum firmum was purchased from DeaGuang in Chuncheon, South Korea. A voucher specimen (HRIC1034) was deposited at the Regional Innovation Center, Hallym University, Chuncheon, South Korea. Roots (1,000 g) were chopped and blended using a Waring blender and then boiled with $2 \mathrm{~L}$ of $80 \%$ ethanol at $80^{\circ} \mathrm{C}$ for $2 \mathrm{~h}$. The insoluble materials were removed through centrifugation at $10,000 \times \mathrm{g}$ for $30 \mathrm{~min}$, and the resulting supernatant was concentrated and freeze-dried to yield a dark brown residue (Yield: $23.5 \%$ ). The chemical were dissolved in dimethyl sulfoxide (DMSO) at a stock solution of 10 $\mathrm{mg} / \mathrm{ml}$ and then it was diluted with medium to obtain the working concentration. Dulbecco's Modified Eagle's Medium (DMEM) and fetal bovine serum (FBS) were obtained from Gibco/BRL (Grand Island, NY). Antibodies against Mcl-1 and Bcl-2 were obtained from Santa Cruz Biotechnology (Santa Cruz, CA). Cleaved caspase-3, Bax and $\beta$-actin were obtained from Cell Signaling Technology (Beverly, MA). All other reagents were of analytical grade or of the highest purity available.

\section{Cell culture}

Human SH-SY5Y neuroblastoma, Rat B103 neuroblastoma, Rat-2 fibroblast and NIH $3 \mathrm{~T} 3$ mouse embryonic fibroblast cells were grown at $37^{\circ} \mathrm{C}$ under a humidified atmosphere of $5 \% \mathrm{CO}_{2}$. The cells were cultured in Dulbecco's Modified Eagle's Medium (DMEM) plus 10\% fetal bovine serum, $50 \mathrm{U} / \mathrm{ml}$ penicillin and 50 $\mu \mathrm{g} / \mathrm{ml}$ streptomycin.

\section{Cell viability assay}

Cell viability was determined using a cytotoxity assay kit, the CCK-8 (Dojindo Lab, Japan) according to the manufacturer's protocol. The cells were plated into 96-wells to a density of $50 \sim 60 \%$ confluence and then the cells were treated with various concentrations of MFRE. After treatment of $24 \mathrm{~h}$, the CCK-8 (10 $\mu \mathrm{l})$ was added to each wells of the plates and incubated the plate for $3 \mathrm{~h}$. A 96-well microtitre plate reader (Molecular Devices) was used to determine the absorbance at $450 \mathrm{~nm}$ for the CCK-8. The mean concentrations in each set of three wells were measured.

\section{Cell morphology}

The cells were plated into 24 -wells plates at $37^{\circ} \mathrm{C}$ under a humidified atmosphere of $5 \% \mathrm{CO}_{2}$. After $24 \mathrm{~h}$ when the density was $50 \sim 60 \%$ confluence and than the cells were treated with various concentrations of MFRE. For the cell morphology experiment, the culture plates were examined under a Bright-Field Microscope $(20 \times)$ and photographed.

\section{Detection of DNA fragmentation}

For detection of apoptotic DNA cleavage, the DNA fragmentation assay was performed using ladder DNA fragmentation assay. In brief, cells were collected after treatment at a various concentrations of MFRE as described in the Fig. legends and washed in PBS. The cells were then lysed with $500 \mu \mathrm{l}$ of genomic 
DNA extration buffer (0.1 M Nacl, 10 mM EDTA, 0.3 M Tris$\mathrm{HCl}, 0.2 \mathrm{M}$ sucrose, $\mathrm{pH} 8.0$ ). The lysate was incubated with $20 \mu \mathrm{l}$ of $10 \%$ SDS solution and incubated at $65^{\circ} \mathrm{C}$ for $30 \mathrm{~min}$. Added $120 \mu \mathrm{l}$ potassium acetate $(\mathrm{pH} 5.3$ ) and stored on ice for $1 \mathrm{~h}$ after that centrifuged for $10 \mathrm{~min}$ at $4^{\circ} \mathrm{C} 12000 \mathrm{rpm}$. Added $2 \mu \mathrm{l}(10$ $\mathrm{mg} / \mathrm{ml}$ ) RNase to supernatant, and incubated for $30 \mathrm{~min}$ at room temperature. The DNA was extracted by washing the resultant pellet in phenol/chloroform extraction and precipitaion by ethanol and then dissoled pellet with distilled water. DNA fragmentation was visualized by electrophoresis in a $0.8 \%$ agarose gel containing ethidium bromide.

\section{Western blot analysis}

SH-SY5Y cells were pretreated with various concentration of MFRE as indicated in each Fig. legend and then washed twice with ice-cold PBS. Cells were lysed in lysis buffer (2\% SDS, $\mathrm{Na}_{3} \mathrm{VO}_{4}$ and protease inhibitor cocktail). After incubation on ice for $10 \mathrm{~min}$ sonicated $10 \mathrm{sec}$ in $10 \%$ amplitude, the lysates were centrifuged (13,000 rpm, $20 \mathrm{~min})$. Supernatants were collected and protein concentrations were determined by Bradford assay (Bio-Rad, Richmond, CA). Equal amounts of protein were separated by SDS-PAGE ( $8 \%$ to $15 \%$ reducing gels), transferred to polyvinylidene difluoride membranes (Millipore, Bedford, MA), and blocked with 5\% non-fat milk. Membranes were incubated in primary antibody overnight at $4^{\circ} \mathrm{C}$. Membranes were then washed in TBST (10 mM Tris, $140 \mathrm{mM} \mathrm{NaCl,} \mathrm{0.1 \%} \mathrm{Tween-20,} \mathrm{pH} \mathrm{7.6),}$ incubated with appropriate secondary antibody, and washed again in TBST. Bands were visualized by enhanced chemiluminescence (ECL) and exposed to X-ray film.

\section{Statistical analysis}

Results were expressed as mean \pm SEM. Statistical significance was analyzed by one-way ANOVA followed by Dunnett's test or paired t-test using Prism 4 (GradPad Software, La Jolla, CA, USA). p $<0.05$ was considered significant.

\section{RESULTS}

\section{Effects of Melandrium firmum root extracts in neurobla- stoma and fibroblast cells}

To determine whether MFRE exerts antitumor effects, we screened the effect of MFRE on the cell viability of malignant neuroblastoma tumor cells and normal fibroblast cells by cell viability assay. The results showed that both human SH-SY5Y and Rat B103 neuroblastoma cells reduced the percentage of viable cells induced by MFRE at $24 \mathrm{~h}$ (Fig. 1). On the other hand, the fibroblast cells such as Rat-2 and Mouse embryonic NIH
3T3 cells showed relatively less cytotoxic effects compared to both malignant neuroblastoma cells at $24 \mathrm{~h}$ (Fig. 1). Therefore, our observation clearly emphasizes that neuroblastoma cancer cell showed relatively higher toxicity than normal fibroblast cell when induced by MFRE, which suggests that MFRE might be an effective and safe anticancer agent. However, the mechanisms by which MFRE exerts its anticancer effects are still not fully understood. To date, there are no studies describing the anticancer effects of MFRE on neuroblastoma cells. The purpose of this study was to investigate whether the MFRE affects the apoptosis of SH-SY5Y through the activation of intrinsic caspases, which might explain mechanisms underlying the antiproliferative and cytotoxicity of cancer cells. Based on our observation, we therefore evaluated human SH-SY5Y neuroblastoma cells for further investigation.

\section{Melandrium firmum root extracts-induced cytotoxicity of human neuroblastoma cells via the process of apoptosis}

To observe the morphological effects of SH-SY5Y cells of MFRE, we examined under a Bright Field Microscope and photographed. It showed that damage cells which had become rounded,
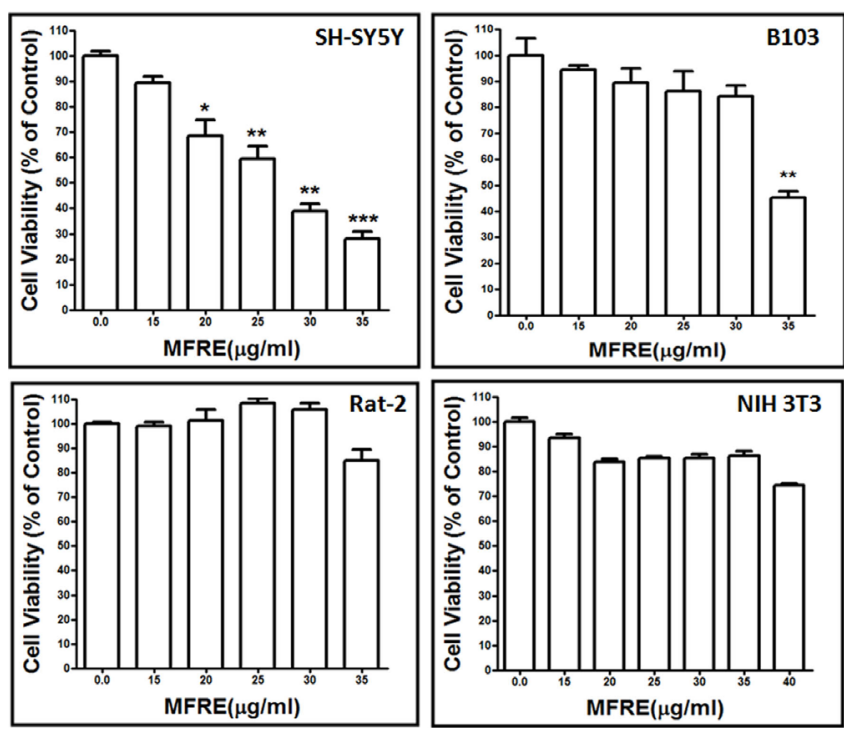

Fig. 1. Cytotoxic effects of MFRE in different cell lines. SH-SY5Y, B103, Rat-2 and NIH 3T3 cells were cultured in 96-well culture dishes to near confluence 50-60\% in DMEM containing 10\% FBS. The cells were treated with various concentrations of SLRE. After treatment of $24 \mathrm{~h}$, the CCK- 8 (10 $\mu$ l, Dojindo Lab) was added to each wells of the plates and incubated the plate for $3 \mathrm{~h}$. A 96-well microtitre plate reader (Molecular Devices) was used to determine the absorbance at $450 \mathrm{~nm}$ for cell viability. Each point is mean \pm SEM of quintuple samples. Data was composed of the mean from three independent experiments in which the activity in the absence of SLRE versus in the presence of MFRE is significantly different $\left(\mathrm{n}=3,{ }^{*} \mathrm{p}<0.05,{ }^{* *} \mathrm{p}<0.01,{ }^{* * *} \mathrm{p}<0.001\right)$. 
A
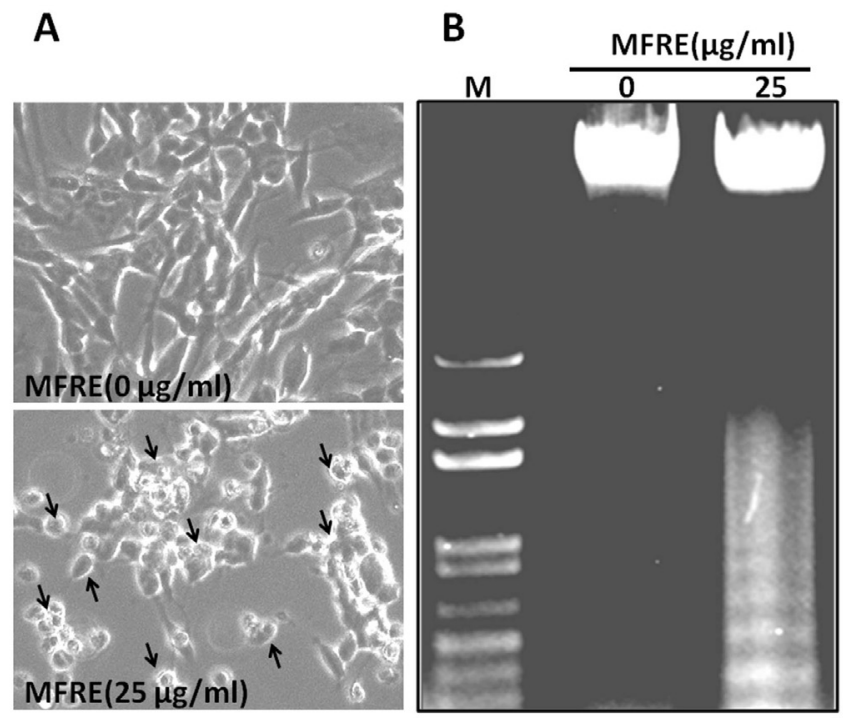

Fig. 2. MFRE reduces cellular viability of SH-SY5Y cells via apoptosis. (A) SH-SY5Y cells were grown in 24-well culture dishes to near confluence $50 \%$ and then cells were treated with 0 and $25 \mu \mathrm{g} / \mathrm{ml}$ of APRE at $24 \mathrm{~h}$ and morphology was observed by Bright-Field Microscopy (20x). Arrows indicate cells with apoptotic morphology. (B) SH-SY5Y cells were grown in $100 \mathrm{~mm}$ culture dishes to near confluence $90 \%$ and then the cells were treated with 0 and $25 \mu \mathrm{g} / \mathrm{ml}$ of MFRE. After $24 \mathrm{~h} \mathrm{MFRE} \mathrm{treatment,}$ the DNA was extracted and separated on a $0.8 \%$ agarose gel containing ethidium bromide. DNA fragments were visualized under UV light. M indicates as a Marker.

neurite retraction, membrane blebbing and shrunken, while the untreated cells were well spread (Fig. 2A). To further confim their morphological effects, we examined internucleosomal DNA fragmentation, which occurs during apoptosis and assessed the result using a DNA gel electrophoresis. Here, we shown that no DNA fragment were found in untreated cells but DNA fragments were observed in cells treated with $25 \mu \mathrm{g} / \mathrm{ml}$ of MFRE, indicating that the cells underwent apoptosis (Fig. 2B). Therefore, these results clearly indicate that the morphological changes of SH-SY5Y cell by MFRE were due to apoptosis which resulted in fragmented DNA.

\section{MFRE-induced cellular death is mediated by intrinsic mitochrondia-mediated pathways}

To examine whether MFRE-induced apoptosis activates the caspase pathway, we incubated SH-SY5Y cells in the absence or presence of MFRE and then harvested the cells for western blot analysis. Because mitochrondian pathway appears to be involved in the induction of intrinsic apoptosis, we measured the levels of anti- and pro-apoptotic protein level which dysregulates mitochrondian balance. Incubation of cells with MFRE dosedependently up-regulated the levels of pro-apoptotic protein Bax and down-regulates anti-apoptotic protein Bcl-2 and $\mathrm{Mcl}$ -

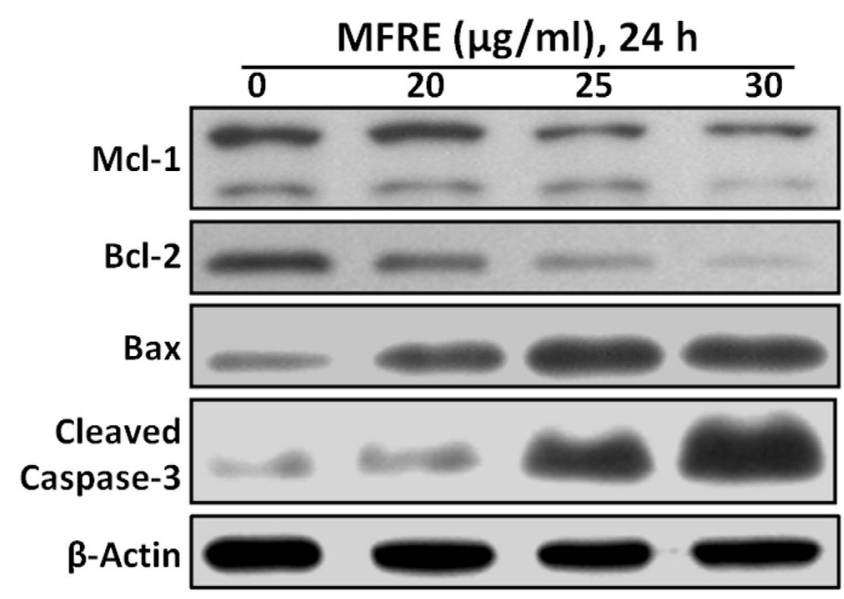

Fig. 3. Apoptosis-related proteins are regulation by MFRE in treated with SH-SY5Y cells. SH-SY5Y cells were cultured in $60-\mathrm{mm}$ culture dishes to near 90\% confluence in DMEM containing 10\% FBS and then cells were treated with 0 to $30 \mu \mathrm{g} / \mathrm{ml}$ of MFRE at $24 \mathrm{~h}$. Whole cell lysates were subjected to $15 \%$ SDS-PAGE and the levels of Mcl-1, Bcl-2, Bax and cleaved caspase- 3 were detected by western blotting as described in materials and methods. $\beta$-actin was used as a loading control.

1 which indicates mitochrondia-mediated apoptisis (Fig. 3). To further determine whether MFRE activates the caspase pathway, we incubated SH-SY5Y cells in the absence or presence of MFRE and then we measured the levels of cleaved caspase-3. Incubation of SH-SY5Y cells with MFRE dose-dependently up-regulated the levels of the biologically active cleaved caspase-3 thereby activating the apoptotic cascade pathway (Fig. 3).Together, this observation suggestes that MFRE treatment can alter the protein levels of key members of the Bcl-2 family and ultimately activates cleaved caspase- 3 thereby initiating the intrinsic apoptotic cascade pathway, which may contribute to the susceptibility of cancer cells to mitochrondial dysfunction.

\section{DISCUSSION}

The present study was designed to define the mechanism(s) of the cellular apoptotic and cytotoxic properties of natural plant extracts because it causes dose-dependent reduction of human SH-SY5Y neuroblastoma cell viability (Fig. 1) by the process of apoptosis which could results in the design of novel approaches for the management of cancer cells. Following this study, our observation clearly emphasizes that neuroblastoma cancer cell showed relatively higher toxicity than normal fibroblast cell when induced by MFRE (Fig. 1), which suggests that Melandrium firmum root extracts might be an effective and safe anticancer agent. However, the mechanisms by which MFRE exerts its anticancer effects are still not fully understood. To date, there are no studies describing 
the anticancer effects of MFRE on cancer cells. The purpose of this study was to investigate whether the MFRE affects the apoptosis of SH-SY5Y cells through the activation of caspases, which might explain mechanisms underlying the apoptosis and cytotoxicity of cancer cells.

Apoptosis, as a regulable biological mode of cell death, included two major types of pathways, namely, the death-receptor-mediated extrinsic pathway and the mitochondria-dependent intrinsic pathway $[16,17]$. Bcl-2 family proteins, as critical checkpoints, play important roles in controlling the mitochondria-dependent intrinsic pathway [18]. So far more than 20 members of Bcl-2 family have been identified in human including sup-apoptosis proteins (such as Bcl-2, Bcl-xL) and pro-apoptosis proteins (such as Bax, Bak) [19]. However, anti-cancer effects of many currently available chemotherapeutics agents may be inhibited by upregulating Bcl-2 expression to block the apoptotic pathway [20]. Thereby, antagonizing the function of Bcl-2 may be a useful strategy for restoring normal apoptotic processes in cancer cells, resulting in the sensitization of cancer cells to chemotherapy. On the other hand, Bax, as a pro-apoptotic member of the Bcl-2 family, was shown to constitute a requisite gateway to the mitochondriadependent pathway of apoptosis [21]. Thus, restoring the sensitivity of cancer cells to anti-tumor agents can also be carried out by up-regulating Bax expression [22]. Bcl-2 and Bax proteins, as two major members of the Bcl-2 family, may form heterodimer complex to cause mutualneutralization of their functions which resulting in apoptosis triggering [23]. Therefore, the balance between the expression levels of $\mathrm{Bcl}-2$ and Bax is critical in determining the fate of cells, survival or death. In this study, downregulated the protein level of Bcl-2 and upregulated Bax (Fig. 3). Therefore, increasing Bcl-2 family protein expression (Bax and $\mathrm{Bcl}-2$ radio) might indicate that MFRE-induced apoptosis strongly correlates with the intrinsic mitochondrial apoptotic signaling pathway. The detail pathways and mechanisms of induction of MFRE in SH-SY5Y neuroblastoma cells warrant further research.

In cancer biology, it is now evident that many cancer cells circumvent normal apoptotic mechanisms to prevent their selfdestruction. However, caspase is one of the key executioners of apoptosis and is triggered via endoplasmic reticulum stress, extracellular stimuli or mitochondrial damage [24, 25]. In particular, caspase-3 plays a pivotal role in the terminal and execution phases of apoptosis induced by diverse stimuli [26]. Upon activation, initiator caspase- 9 triggers the proteolytic activation of the executioner caspase- $3 /-7$ and caspase- 8 in a process that results in the cleavage of PARP and subsequent DNA degradation and apoptotic death $[27,28]$. In the present study, treatment of SH-SY5Y cells to MFRE resulted in a dramatic increase in the proteolytic activation of caspase-3 (Fig. 3), which is the main executioner of apoptosis. As expected, caspase-3 degraded clearly in a concentration-dependent manner which correlated with a caspase signaling pathway and apoptosis that finally fragment DNA. Therefore, MFRE might be used as a potential apoptosis inducing agent in neuroblastoma cancer cells for the development of anticancer drugs.

In conclusion, the present study we examined intrinsic apoptosis as the mechanism underlying MFRE-induced cellular apoptosis and cytotoxicity in human neuroblastoma cells rather than normal fibroblast cells. As far as we know, this is the first report to demonstrate that MFRE was dose-dependently activated caspase signaling triggered by the modulation of Bcl-2 family proteins which results in the accumulation of fragmented DNA in SH-SY5Y cells. These findings suggest that MFRE may serve as a potent chemosensitizer in the treatment of human cancers. Therefore, these results warrant further investigation of MFRE as a source of pharmacologically active agents and the assessment of their anti-tumor therapeutic efficacy in vivo in experimental brain tumor models.

\section{ACKNOWLEDGEMENTS}

This research was supported by Basic Science Research Program through the National Research Foundation of Korea (NRF) funded by the Ministry of Education, Science and Technology (NRF-2010-0013043) and by Basic Science Research Program through the National Research Foundation of Korea (NRF) funded by the Ministry of Education (NRF-2009-0094071), the Republic of Korea.

\section{REFERENCES}

1. Perry LM, Metzger J (1980) Medicinal plants of East and Southeast Asia: attributed properties and uses, p 74. MIT Press, Cambridge, MA.

2. Chang IS, Han YB, Woo WS, Kang SS, Lotter H, Wagner H (1989) Sapogenins from Melandrium firmum. Planta Med 55:544-547.

3. Woo EH, Woo WS, Chmurny GN, Hilton BD (1992) Melandrioside A, a saponin from Melandrium firmum. J Nat Prod 55:786-794.

4. Zheng MS, Hwang NK, Kim DH, Moon TC, Son JK, Chang HW (2008) Chemical constituents of Melandrium firmum Rohrbach and their anti-inflammatory activity. Arch Pharm Res 31:318-322.

5. Bénard J, Raguénez G, Kauffmann A, Valent A, Ripoche 
H, Joulin V, Job B, Danglot G, Cantais S, Robert T, TerrierLacombe MJ, Chassevent A, Koscielny S, Fischer M, Berthold F, Lipinski M, Tursz T, Dessen P, Lazar V, Valteau-Couanet D (2008) MYCN-non-amplified metastatic neuroblastoma with good prognosis and spontaneous regression: a molecular portrait of stage 4S. Mol Oncol 2:261-271.

6. Maris JM, Hogarty MD, Bagatell R, Cohn SL (2007) Neuroblastoma. Lancet 369:2106-2120.

7. Castel V, Grau E, Noguera R, Martínez F (2007) Molecular biology of neuroblastoma. Clin Transl Oncol 9:478-483.

8. Deorukhkar A, Krishnan S, Sethi G, Aggarwal BB (2007) Back to basics: how natural products can provide the basis for new therapeutics. Expert Opin Investig Drugs 16:1753-1773.

9. Kim R (2005) Recent advances in understanding the cell death pathways activated by anticancer therapy. Cancer 103: 1551-1560.

10. Orrenius S (2004) Mitochondrial regulation of apoptotic cell death. Toxicol Lett 149:19-23.

11. Sakahira H, Enari M, Nagata S (1998) Cleavage of CAD inhibitor in CAD activation and DNA degradation during apoptosis. Nature 391:96-99.

12. Moore JO, Palep SR, Saladi RN, Gao D, Wang Y, Phelps RG, Lebwohl MG, Wei H (2004) Effects of ultraviolet B exposure on the expression of proliferating cell nuclear antigen in murine skin. Photochem Photobiol 80:587-595.

13. Hong WK, Sporn MB (1997) Recent advances in chemoprevention of cancer. Science 278:1073-1077.

14. Kelloff GJ, Crowell JA, Steele VE, Lubet RA, Malone WA, Boone CW, Kopelovich L, Hawk ET, Lieberman R, Lawrence JA, Ali I, Viner JL, Sigman CC (2000) Progress in cancer chemoprevention: development of diet-derived chemopreventive agents. J Nutr 130:467S-471S.

15. Sporn MB, Suh N (2000) Chemoprevention of cancer. Carcinogenesis 21:525-530.

16. Wyllie AH (1997) Apoptosis: an overview. Br Med Bull
53:451-465

17. Ashkenazi A, Dixit VM (1998) Death receptors: signaling and modulation. Science 281:1305-1308.

18. Kroemer G (1997) The proto-oncogene Bcl-2 and its role in regulating apoptosis. Nat Med 3:614-620.

19. Antonsson B, Martinou JC (2000) The Bcl-2 protein family. Exp Cell Res 256:50-57.

20. Reed JC (1997) Double identity for proteins of the Bcl-2 family. Nature 387:773-776.

21. Wei MC, Zong WX, Cheng EH, Lindsten T, Panoutsakopoulou V, Ross AJ, Roth KA, MacGregor GR, Thompson CB, Korsmeyer SJ (2001) Proapoptotic BAX and BAK: a requisite gateway to mitochondrial dysfunction and death. Science 292:727-730.

22. Zhang CL, Wu LJ, Tashiro S, Onodera S, Ikejima T (2004) Oridonin induces apoptosis of HeLa cells via altering expression of Bcl-2/Bax and activating caspase-3/ICAD pathway. Acta Pharmacol Sin 25:691-698.

23. Nascimento Pde S, Ornellas AA, Campos MM, Scheiner MA, Fiedler W, Alves G (2004) Bax and bcl-2 imbalance and HPB infection in penile tumors and adjacent tissues. Prog Urol 14:353-359.

24. Budihardjo I, Oliver H, Lutter M, Luo X, Wang X (1999) Biochemical pathways of caspase activation during apoptosis. Annu Rev Cell Dev Biol 15:269-290.

25. Cecconi F, Gruss P (2001) Apaf1 in developmental apoptosis and cancer: how many ways to die? Cell Mol Life Sci 58:16881697.

26. Thornberry NA, Lazebnik Y (1998) Caspases: enemies within. Science 281:1312-1316

27. Kuida K (2000) Caspase-9. Int J Biochem Cell Biol 32:121124.

28. Cain K, Bratton SB, Cohen GM (2002) The Apaf-1 apoptosome: a large caspase-activating complex. Biochimie 84:203214. 